\title{
High-Efficiency CdTe and CIGS Thin-Film Solar Cells: Highlights and Challenges
}

Conference Paper NREL/CP-520-39894

May 2006

\section{Preprint}

R. Noufi and K. Zweibel

Presented at the 2006 IEEE $4^{\text {th }}$ World Conference on Photovoltaic Energy Conversion (WCPEC-4)

Waikoloa, Hawaii

May 7-12, 2006 


\section{NOTICE}

The submitted manuscript has been offered by an employee of the Midwest Research Institute (MRI), a contractor of the US Government under Contract No. DE-AC36-99G010337. Accordingly, the US Government and MRI retain a nonexclusive royalty-free license to publish or reproduce the published form of this contribution, or allow others to do so, for US Government purposes.

This report was prepared as an account of work sponsored by an agency of the United States government. Neither the United States government nor any agency thereof, nor any of their employees, makes any warranty, express or implied, or assumes any legal liability or responsibility for the accuracy, completeness, or usefulness of any information, apparatus, product, or process disclosed, or represents that its use would not infringe privately owned rights. Reference herein to any specific commercial product, process, or service by trade name, trademark, manufacturer, or otherwise does not necessarily constitute or imply its endorsement, recommendation, or favoring by the United States government or any agency thereof. The views and opinions of authors expressed herein do not necessarily state or reflect those of the United States government or any agency thereof.

Available electronically at http://www.osti.gov/bridge

Available for a processing fee to U.S. Department of Energy and its contractors, in paper, from:

U.S. Department of Energy

Office of Scientific and Technical Information

P.O. Box 62

Oak Ridge, TN 37831-0062

phone: 865.576 .8401

fax: 865.576 .5728

email: mailto:reports@adonis.osti.gov

Available for sale to the public, in paper, from:

U.S. Department of Commerce

National Technical Information Service

5285 Port Royal Road

Springfield, VA 22161

phone: 800.553 .6847

fax: 703.605.6900

email: orders@ntis.fedworld.gov

online ordering: http://www.ntis.gov/ordering.htm 


\title{
HIGH-EFFICIENCY CDTE AND CIGS THIN-FILM SOLAR CELLS: HIGHLIGHTS AND CHALLENGES*
}

\author{
Rommel Noufi and Ken Zweibel \\ National Renewable Energy Laboratory, Golden, CO 80401, USA
}

\begin{abstract}
Thin-film photovoltaic (PV) modules of CdTe and $\mathrm{Cu}(\mathrm{In}, \mathrm{Ga}) \mathrm{Se}_{2}$ (CIGS) have the potential to reach costeffective PV-generated electricity. These technologies have transitioned from the laboratory to the market place. Pilot production and first-time manufacturing are ramping up to higher capacity and enjoying a flood of venturecapital funding. CIGS solar cells and modules have achieved $19.5 \%$ and $13 \%$ efficiencies, respectively. Likewise, CdTe cells and modules have reached $16.5 \%$ and $10.2 \%$ efficiencies, respectively. Even higher efficiencies from the laboratory and from the manufacturing line are only a matter of time. Manufacturing-line yield continues to improve and is surpassing $85 \%$. Long-term stability has been demonstrated for both technologies; however, some failures in the field have also been observed, emphasizing the critical need for understanding degradation mechanisms and packaging options. These two thin-film technologies have a common device/module structure: substrate, base electrode, absorber, junction layer, top electrode, patterning steps for monolithic integration, and encapsulation. The monolithic integration of thin-film solar cells can lead to significant manufacturing cost reduction compared to crystalline $\mathrm{Si}$ technology. The $\mathrm{CdTe}$ and CIGS modules share common structural elements. In principle, this commonality should lead to similar manufacturing cost per unit area, and thus, the module efficiency becomes the discriminating factor that determines the cost per watt. The long-term potential of the two technologies require R\&D emphasis on science and engineering-based challenges to find solutions to achieve targeted cost-effective module performance, and in-field durability. Some of the challenges are common to both, e.g., in-situ process control and diagnostics, thinner absorber, understanding degradation mechanisms, protection from water vapor, and innovation in high-speed processing and module design. Other topics are specific to the technology, such as lower-cost and fast-deposition processes for CIGS, and improved back contact and voltage for CdTe devices.
\end{abstract}

\section{INTRODUCTION}

Rapid technical progress has occurred in both the CdTe and $\mathrm{Cu}(\mathrm{In}, \mathrm{Ga}) \mathrm{Se}_{2}$ (CIGS) thin-film PV technologies. Advances have been made in the following areas: materials delivery and film growth, control of film properties at the micro and nano levels, understanding how the device works (device physics) and how to improve the properties of individual layers, intrinsic device stability, and prototype module reliability. The results from these advances have helped both technologies evolve from the laboratory to the marketplace. The existing industry, joined by new start-up entities supported by venture capital, continues to work toward expanded capacity from pilot production to first-time manufacturing and beyond. Perhaps the most impressive advance is the success by First Solar, which is transitioning toward a 75MW capacity to produce commercial CdTe modules with power output greater than $67 \mathrm{~W}$.

In this paper, we present highlights of the CIGS and CdTe technologies, and address key challenges that need to be overcome to accelerate the commercialization of the two technologies.

\section{HIGHLIGHTS OF CIGS AND CdTe TECHNOLOGIES}

Laboratory Devices. The CIGS thin film belongs to the multinary Cu-chalcopyrite system, where the bandgap can be modified by varying the Group III (on the Periodic Table) cations among $\mathrm{In}, \mathrm{Ga}$, and $\mathrm{Al}$ and the anions between $S e$ and $S[1,2]$. A wide range of bandgaps can be obtained using combinations of different compositions. The bandgap range of interest for this technology is between 1 and $1.7 \mathrm{eV}[3]$. The CdTe material in the device mostly exists as a binary with a slight deviation from stoichiometry. Its bandgap is about $1.5 \mathrm{eV}$, which is a good match to the solar spectrum. In the device, this bandgap may vary somewhat as a result of its interaction with the CdS ( 2.4-eV bandgap) heterojunction partner during processing [4]. Table 11 summarizes champion efficiencies of $\mathrm{CdTe}$ devices and $\mathrm{Cu}(\mathrm{In}, \mathrm{Ga}, \mathrm{Al})(\mathrm{Se}, \mathrm{S})_{2}-$ based devices of different compositions.

Table 2 compares champion efficiency and power of different commercial-sized CIGS, CIGSS, and CdTe modules from leading companies. The results show that the performance of the CIGS and CdTe modules are now approaching that of polycrystalline silicon PV. In addition to improved efficiency, we also see demonstrated high throughputs and/or higher yields.

Figure 1 shows a schematic of the CdTe and CIGS device structure. Individual layer thicknesses are approximate and may differ somewhat among laboratories. For

*This work has been authored by an employee or employees of the Midwest Research Institute under Contract No. DE-AC36-99GO10337 with the U.S. Department of Energy. The United States Government retains and the publisher, by accepting the article for publication, acknowledges that the United States Government retains a non-exclusive, paid-up, irrevocable, worldwide license to publish or reproduce the published form of this work, or allow others to do so, for United States Government purposes. 


\begin{tabular}{|c|c|c|c|c|c|c|c|}
\hline & Area & $V_{O C}$ & $\mathrm{~J}_{\mathrm{SC}}$ & FF & Efficienc & \multicolumn{2}{|c|}{ Comments } \\
\hline CIGSe & 0.410 & 0.697 & 35.1 & 79.52 & 19.5 & CIGSe/CdS/Cell & NREL, 3-stage process \\
\hline CIGSe & 0.402 & 0.670 & 35.1 & 78.78 & 18.5 & CIGSe/ZnS $(\mathrm{O}, \mathrm{OH})$ & NREL, Nakada et al. \\
\hline CIGS & 0.409 & 0.830 & 20.9 & 69.13 & 12.0 & $\mathrm{Cu}(\ln , \mathrm{Ga}) \mathbf{S}_{2} / \mathrm{CdS}$ & Dhere, FSEC \\
\hline CIAS & - & 0.621 & 36.0 & 75.50 & 16.9 & $\mathrm{Cu}(\ln , \mathbf{A l}) \mathrm{Se}_{2} / \mathrm{CdS}$ & $\mathrm{IEC}, \mathrm{Eg}=1.15 \mathrm{eV}$ \\
\hline CdTe & 1.03 & 0.845 & 25.9 & 75.51 & 16.5 & CTO/ZTO/CdS/CdTe & NREL, CSS \\
\hline CdTe & - & 0.840 & 24.4 & 65.00 & 13.3 & $\mathrm{SnO}_{2} / \mathrm{Ga}_{2} \mathrm{O}_{3} / \mathrm{CdS} / \mathrm{CdTe}$ & IEC, VTD \\
\hline CdTe & 0.16 & 0.814 & 23.56 & 73.25 & 14.0 & ZnO/CdS/CdTe/Metal & U. of Toledo, sputtered \\
\hline
\end{tabular}

Table 1. Thin Film CIGS Solar Cells Efficiencies

\begin{tabular}{|l|c|c|c|c|c|}
\hline \multicolumn{1}{|c|}{ Company } & Device & $\begin{array}{c}\text { Aperture Area } \\
\left(\mathrm{cm}^{2}\right)\end{array}$ & Efficiency (\%) & Power (W) & Date \\
\hline Global Solar & CIGS & 8390 & $10.2^{*}$ & $88.9^{*}$ & $05 / 05$ \\
\hline Shell Solar & CIGSS & 7376 & $11.7^{*}$ & $86.1^{*}$ & $10 / 05$ \\
\hline Würth Solar & CIGS & 6500 & 13.0 & 84.6 & $06 / 04$ \\
\hline First Solar & CdTe & 6623 & $10.2^{*}$ & $67.5^{*}$ & $02 / 04$ \\
\hline Shell Solar GmbH & CIGSS & 4938 & 13.1 & 64.8 & $05 / 03$ \\
\hline Antec Solar & CdTe & 6633 & 7.3 & 52.3 & $06 / 04$ \\
\hline Shell Solar & CIGSS & 3626 & $12.8^{*}$ & $46.5^{*}$ & $03 / 03$ \\
\hline Showa Shell & CIGS & 3600 & 12.8 & 44.15 & $05 / 03$ \\
\hline
\end{tabular}

Table 2. Polycrystalline Thin Film PV Modules

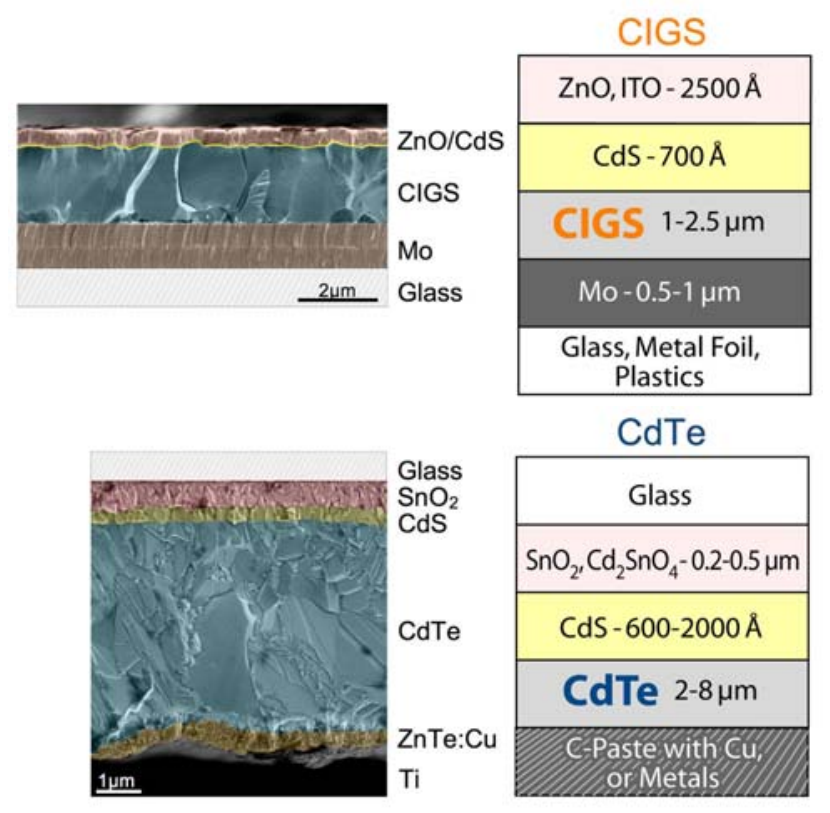

Fig. 1. CdTe and CIGS Device Structure

comparison, cross sections of scanning electron micrographs are shown to provide true physical perspectives of the structures. Note that the CIGS device is a substrate configuration that starts with glass/base electrode, whereas the CdTe device is a superstrate configuration that starts with glass/transparent top electrode. The sequence of the growth of the layers in both structures may influence the properties of the front and back junctions - that is, the $p / n$ interface and the back contact-and, in turn, the efficiency of the devices.

The most common deposition methods for the CdTe device involve acquiring commercial $\mathrm{SnO}_{2}$-coated glass, or the deposition of cadmium stannate and zinc stannate by sputtering, followed by chemical-bath deposition (CBD) of CdS. The CdTe thin-film absorber is usually applied by close-spaced sublimation, vapor-transport deposition, or electrodeposition, followed by $\mathrm{CdCl}_{2}$ treatment. The back contact is then applied after a chemical preparation (etching) of the back surface of CdTe. The nature of the back contact varies-from a carbon paste containing $\mathrm{Cu}_{x} \mathrm{Te}$ and $\mathrm{HgTe}$, to a combination of other metals with $\mathrm{Cu}$. The inclusion of a form of $\mathrm{Cu}$, with the back contact, is necessary; its effect on the performance and stability of the device is the subject of intense investigations. $[5,6]$

The CIGS device starts with sputtered Mo on glass. The Mo film properties have to be optimized for adhesion, sheet resistance, and morphology where it allows sodium ( $\mathrm{Na}$ ) from the glass to diffuse through to the CIGS layer. Sodium aids the CIGS grain growth and increases the carrier concentration. The optimum concentration of $\mathrm{Na}$ is about $0.1 \%$ (atomic). Growth on non-Na-containing substrates requires dosing of the CIGS film by introducing a 60 to $120 \AA \mathrm{NaF}$ layer on the Mo back contact, or introducing $\mathrm{NaF}$ during the CIGS deposition. The absence of $\mathrm{Na}$ in the device reduces the efficiency by $2 \%$ to $3 \%$ (absolute). The CIGS absorber is deposited using several methods of flux delivery: evaporation of elements simultaneously or in a prescribed sequence, sputtering of metals followed by selenization with $\mathrm{H}_{2} \mathrm{Se}$, reactive sputtering of metals with Se vapor, or printing of metals 
from ink precursors followed by selenization. The latter method requires no vacuum. The CdS layer is applied by CBD, followed by sputter deposition of a bilayer consisting of intrinsic and conducting $\mathrm{ZnO}$. The $\mathrm{ZnO}$ layer is also applied by using the chemical-vapor deposition process. The industrial processes for both technologies basically adopt combinations of the techniques, as described above.

The CIGS and CdTe modules share common characteristics and device structural elements. Therefore, in principle, the cost per unit area should be similar, and, thus, the efficiency becomes a discriminating factor for the cost/watt. However, in practice, production processes in terms of throughput and yield can differ significantly and may offset the advantage of higher performance. This is the case at this time, where the cost of producing CdTe modules has an advantage over CIGS. In future years, semiconductor costs may become more prominent drivers.

The long-term potential of the two technologies requires R\&D emphasis on science and engineering-based challenges to find solutions to achieve targeted, costeffective module performance and in-field durability. Scientists and engineers in the thin-film community have demonstrated some successes in this regard. Transitioning knowledge, especially in the area of production processes, from the laboratory to manufacturing has proven much more difficult than anticipated. Because of the inherent complexity of the two compound semiconductors, much more research is needed.

Challenges. We list some key challenges that must be addressed to accelerate progress and contribute to commercial success. The list is not comprehensive and does not go into detail due to lack of space.

1. Science and Engineering Support. There is a great need to enhance the science and engineering knowledge base from which to (a) derive measurable material properties that are predictive of device and module performance, (b) model the relationship between film growth and material delivery, and (c) couple this knowledge to industrial processes. The beneficial impacts expected are higher throughput and yield at every step of the process, and a higher degree of reliability and reproducibility, which, of course, will lead to higher performance.

2. Long-Term Stability. Both technologies have shown long-term stability. However, degradation of performance has also been observed. So, why do some modules maintain stable performance, while others fail? This question begs for a better understanding of degradation mechanisms at the device level and prototype module level, to distinguish the intrinsic device contributions from the extrinsic mechanisms that may result from the packaging process. Infiltration of water vapor through the encapsulation package has been shown to degrade performance. Hence, developing a thin-film barrier to water vapor will boost in-field durability. Much work has been done to monitor and investigate performance of CIGS and CdTe modules in the outdoors. To date, the level of understanding the causes of performance degradation is inadequate and lacks the coupling of feedback from device- and module-level studies. Recently, Albin et al. $[7,8,9]$ at NREL investigated the temperaturedependent degradation of CdTe devices. The findings point out that different mechanisms dominate degradation at different temperatures. From $90^{\circ}$ to $120^{\circ} \mathrm{C}$, the degradation is dominated by $\mathrm{Cu}$ diffusion from the back contact toward the electrical junction, whereas the source of possible degradation from $60^{\circ}$ to $90^{\circ} \mathrm{C}$ is not currently known, and may simply reflect straying outside a process window. Such studies help to identify relevant and appropriate accelerated test protocols. Another issue requiring further consideration is the need for encapsulants that can be applied and cured at room temperature and that are chemically inert toward the semiconductor layer with which they come in contact.

3. In-Situ Process Diagnostics and Control. To date, very little exists in the area of in-situ diagnostics and control for both the CIGS and CdTe technologies. This situation is because science-based knowledge of material properties is inadequate to serve as a solid foundation from which diagnostics tools can be developed. These tools must be developed such that they can respond to rapid processing and feedback for adjusting real-time processes. The results will impact throughput and yield, and will make the process reproducible and reliable. Currently, only a few techniques are in practice, based on changes of emissivity from the growing surface, and in-situ monitoring of composition using X-ray fluorescence.

4. Thinner CIGS and CdTe Absorbers. This challenge is motivated by concerns over the availability and price of In and Te. This concern currently seems more severe for In than Te because of competing uses (flat panel displays). For example, the availability of In will begin to have a significant impact at a production capacity level of tens of gigawatts. Reducing the absorber thickness also yields other benefits, especially for CIGS-for example, higher throughput and less material cost. The primary challenge will be to thin the absorber to below $0.5 \mu \mathrm{m}$, while maintaining state-of-the-art performance. Potential pitfalls also exist for going very thin, including nonuniformity, shunting/pinholes, lower yields, and a need to change device structure from the current norm. Table 3 summarizes the status of performance for laboratory devices for very thin CIGS and CdTe absorbers [10,11]. The drop in performance, currently begins to become significant below a thickness of $1 \mu \mathrm{m}$, but that is likely an artifact of our rudimentary knowledge. Studies guided by device modeling are under way to understand the loss mechanism for very thin absorbers $[12,13]$.

\section{Need for High-Throughput, Low-Cost Processes.}

This challenge is more relevant to CIGS technology. Currently, the best-performing devices and large modules are produced in two ways: by evaporation of the elements in vacuum; and by sputtering of the metals, followed by selenization with $\mathrm{H}_{2} \mathrm{Se}$. These two processes suffer from 
relatively slow throughput, poor material utilization, and relatively high vacuum. Deposition by high-rate cosputtering from cylindrical magnetrons is now being pursued; however, to date, this approach has not demonstrated state-of-the-art performance. A lower-cost process should feature high deposition rates, high material utilization, and simpler equipment capable of processing very large substrates. One such example is a process that uses nano-components to make printable precursors that are crystallized into CIGS [14,15].

\begin{tabular}{|cc|c|c|c|l|}
\hline \multicolumn{2}{|c|}{$\mathrm{t}(\mu \mathrm{m})$} & $\mathrm{V}_{\mathrm{OC}}(\mathrm{V})$ & $\begin{array}{c}\mathrm{J}_{\mathrm{SC}} \\
\left(\mathrm{mA} / \mathrm{cm}^{2}\right)\end{array}$ & $\begin{array}{c}\mathrm{FF} \\
(\%)\end{array}$ & $\begin{array}{l}\text { Efficiency } \\
(\%)\end{array}$ \\
\hline 1.0 & CIGS & 0.676 & 31.96 & 79.47 & $\begin{array}{l}17.16 \\
\mathrm{NREL}\end{array}$ \\
\hline 0.75 & CIGS & 0.652 & 26.0 & 74.0 & 12.5 \\
\hline 0.40 & CIGS & 0.565 & 21.3 & 75.7 & 9.1 \\
\hline 0.47 & CIGS & 0.576 & 26.8 & 64.2 & $\begin{array}{l}9.9 \\
\text { EPV }\end{array}$ \\
\hline 1. & $\begin{array}{c}\text { CIGSS } \\
\text { Module }\end{array}$ & 25.26 & 2.66 & 69.2 & $\begin{array}{l}12.8 \\
\text { Shell } \\
\text { Solar }\end{array}$ \\
\hline 0.87 & CdTe & 0.772 & 22.0 & 69.7 & $\begin{array}{l}11.8 \\
\text { U. of } \\
\text { Toledo }\end{array}$ \\
\hline
\end{tabular}

Table 3. Summary-Thin Cells Efficiencies

6. Improved Open-Circuit Voltage $\left(\mathrm{V}_{\mathrm{oc}}\right)$ in $\mathrm{CdTe}$ Devices. The primary parameter needed to improve and achieve high efficiency in CdTe devices is $V_{\text {oc }}$, whose magnitude is affected by junction properties, bulk carrier concentration, and the back contact. Enhanced $\mathrm{V}_{\mathrm{oc}}$ may be achieved by increasing the net p-type doping of the bulk through extrinsic doping, or, more likely, by better crystal growth conditions that influence more favorable formation of native point defects.

\section{ACKNOWLEDGEMENTS}

The authors acknowledge contributions to this paper from: Polycrystalline Thin Film Group, Measurement and Characterization, K. Zweibel, H. Ullal, B. von Roedern NREL, Dale Tarrant - Shell Solar Industries, Robert Birkmire - IEC, U. of Delaware, Bernhard Dimmler Wurth Solar, Dennis Hollars - MIASOLE, Jeff Britt and Scott Wiedeman - Global Solar Energy, Tim Anderson U. of Florida, and W.S. Sampath - AVA Tech, Peter Meyers - First Solar. This work is support or funded under DOE Contract No. DE-AC36-99G010337.

\section{REFERENCES}

1. U. Rau and H.W. Schock, Appl. Phys. A69,131 (1999).

2. I. Hengel, R. Klenk, E. Garcia Villora, and M.-Ch. LuxSteiner, Proc. $2^{\text {nd }}$ World Conf. Exh. Photovol. Sol. Energy Conv. 545 (1996).

3. D. S. Albin, J. Carapella, J. R. Tuttle, and R. Noufi, Mat. Res. Soc. Symp. Proc. Vol. 228, 267 (1992).

4. B. McCandless and J.R. Sites, Handbook of Photovoltaic Science and Engineering, Edit., A. Luque and S. Hegedus, Wiley, West Sussex, England, 2003, p.637.

5. K. Dobson, I. Visoly-Fisher, G. Hodes, D. Cahen, Solar Energy Materials and Solar Cells, 62, 295 (2000).

6. T.A. Gessert, S. Smith, T. Moriarty, M. Young, S. Asher, S. Johnston, A. Duda, and C. DeHart, Proc. $31^{\text {st }}$ IEEE PV Specialists Conf. ( IEEE, Piscataway, NJ, 2005) pp. 291-294.

7. D.S. Albin, S.H. Demtsu, and T.J. McMahon, submitted to Thin Solid Films (2005), in review.

8. D.Albin, T. McMahon, T. Berniard, J. Pankow, S. Demtsu, and R. Noufi, Proc. 31st IEEE Photovoltaic Specialists Conference, IEEE, New York, 2005315.

9. D.S. Albin, and S.H. Demtsu, to be published.

10. A. Gupta and A.D. Compaan, $31^{\text {st }}$ IEEE PV Specialists Conference (IEEE, Piscataway, NY, 2005) p. 235

11. K. Ramanathan, R. Noufi, B. To, D. L. Young, R. J. Dhere, R. Bhattacharya, M.A. Contreras, and G. Teeter, In these Proceedings

12. M. Gloeckler and J. R. Sites, J. Appl. Phys. 98, 103703 (2005)

13. M. Gloeckler and J.R. Sites, CIGS National Team Meeting, April 2006, Private Communications.

14. V.K. Kapur, A. Bansal, P. Le, and O.I. Asensio, "NonVacuum Processing for CIGS Solar Cells on Rigid and

Flexible Substrates, Proc. 29th IEEE PV Spec. Conf (New Orleans, 05/2002), 688.

15 C. Eberspacher, K. Pauls, and J. Serra, "Non-Vacuum Processing of CIGS Solar Cells," Proc. 29thIEEE PV Spec. Conf (New Orleans, 05/2002), 684. 